\title{
Infração juvenil feminina e socioeducação: um enfoque cultural e de gênero
}

\section{Female juvenile offense and socio-education: through a gender and cultural lens}

\section{Delincuencia juvenil femenina y socioeducación: un enfoque cultural y de género}

\author{
Maria Cláudia Santos Lopes de Oliveira* \\ Universidade de Brasília - UnB, Brasília, Distrito Federal, Brasil \\ Daniela Lemos Pantoja Costa** \\ Universidade de Brasília - UnB, Brasília, Distrito Federal, Brasil
}

\section{Carolina Knihs de Camargo***}

Universidade de Brasília - UnB, Brasília, Distrito Federal, Brasil

\begin{abstract}
RESUMO
O presente artigo analisa resultados de uma pesquisa-intervenção, em que se investigou como as adolescentes em medida socioeducativa estrita de liberdade vivenciam os efeitos dos valores de gênero predominantes no sistema de justiça juvenil. Realizou-se uma Oficina de Gênero, com 10 encontros e 11 participantes do sexo feminino. Os posicionamentos que emergiram em diálogos, durante os encontros, foram analisados, chegandose a quatro categorias: (a) (des)igualdade de direitos entre os gêneros; (b) estereótipos sobre o comportamento infracional feminino; (c) invisibilização da mulher; (d) impactos da lógica social repressiva sobre as adolescentes. Discute-se que: as adolescentes infratoras são objeto de um duplo estigma - como adolescentes em conflito com a lei e como pessoas do sexo feminino; os princípios garantistas e protetivos da lei não impedem que ocorra preconceito e discriminação de gênero, tornando as necessidades e perspectivas das adolescentes invisíveis ao sistema socioeducativo, onde persiste uma orientação para objetivos repressiva e sexista, que se converte em barreira para a igualdade de oportunidades de desenvolvimento humano, entre meninos e meninas.
\end{abstract}

Palavras-chave: adolescência, gênero, socioeducação, pesquisaintervenção.

\section{ABSTRACT}

This article reviews the results of a research intervention aimed to investigate how female adolescents in detention experience the effects of the gender values prevailing in the juvenile justice system. A Gender Workshop was held comprising 10 meetings and 11 female participants. The positions that emerged in dialogues during the meetings were analyzed and 
four categories were determined: (a) (in)equality of rights between genders; (b) stereotypes about female offending behavior; (c) women's invisibility; (d) impacts of repressive social logic on adolescents. It is argued that: female adolescent offenders are subject to double stigma - as adolescents in conflict with the law and as female persons; the guarantor and protective principles of the law do not prevent prejudice and gender discrimination from occurring, making the needs and perspectives of female adolescents invisible to the socio-educational system, where a repressive and sexist orientation persists, raising a barrier against equal human development opportunities between boys and girls.

Keywords: adolescence, gender, socio-education, research intervention.

\section{RESUMEN}

Este artículo analiza los resultados de una investigación-intervención en la que se investigó cómo las adolescentes privadas de libertad por estar cumpliendo medidas socioeducativas vivencian los efectos de los valores de género que predominan en el sistema de justicia juvenil. Un Taller de Género se realizó con 10 encuentros y con la participación de 11 chicas. El análisis de los posicionamientos que surgieron en los diálogos, durante los encuentros, resultaron en cuatro categorías: (a) (des)igualdad de derechos entre los géneros; (b) estereotipos acerca del comportamiento delictivo femenino; (c) invisibilidad de las mujeres; e (d) impactos de la lógica social represiva sobre las adolescentes. Se discute que: las adolescentes infractoras son objeto de un doble estigma - como adolescentes en conflicto con la ley penal y como personas del sexo femenino; los principios de garantía de derechos y protección de la ley no impiden que ocurran prejuicios y discriminaciones de género, haciendo invisibles las necesidades y perspectivas de las adolescentes por el sistema socioeducativo, donde persiste una inclinación hacia objetivos represivos y sexistas, que se convierten en barreras contra la igualdad de oportunidades para el desarrollo humano, entre niños y niñas.

Palabras clave: adolescencia, género, socioeducación, investigaciónintervención.

\section{I ntrodução}

O atendimento socioeducativo a adolescentes que cometeram infrações análogas a crimes está previsto na Constituição Federal (Brasil, 1988) e no Estatuto da Criança e do Adolescente, lei 8.069, de 13 de julho de 1990, também conhecida como ECA (BRASIL, 1990). A execução das medidas socioeducativas vem sendo orientada, desde 2006, pela Resolução 119 do CONANDA (2006), que inspirou a Lei 12.594, de 18 de janeiro de 2012, a qual institui e formaliza o SINASE - Sistema Nacional de Atendimento Socioeducativo (BRASIL, 2012). A implantação do SINASE "objetiva primordialmente o desenvolvimento de uma ação socioeducativa sustentada nos princípios dos direitos humanos [...] estruturada, principalmente, em bases éticas e pedagógicas" (BRASIL, 2006, p.16). Assim sendo, seguindo os mesmos princípios, garantidores da proteção e orientados aos direitos humanos, que regem o cuidado às 
crianças e adolescentes, o atendimento socioeducativo deve resguardar plenamente os direitos sociais dos/as autores/as de ato infracional.

Entretanto, no cotidiano do atendimento socioeducativo, esses princípios nem sempre têm sido observados e os/as adolescentes podem se tornar o alvo de preconceito, discriminação e baixas expectativas. Estudos evidenciam que as adolescentes que cometem atos infracionais lidam com dificuldades ainda maiores do que os adolescentes. O universo socioeducativo é fortemente marcado por uma cultura masculina e misógina (Abramovay et al., 2010; Assis \& Constantino, 2001; Costa, 2015; Lopes de Oliveira \& Yokoy de Souza, 2012), onde ainda hoje predominam significados e concepções de gênero naturalizantes e deterministas. Tais características, apontadas pelos estudos, contribuem para converter as adolescentes em alvos de dispositivos mais acirrados de exclusão social, preconceito e desrespeito que os adolescentes. Segundo Abramovay et al. (2010, p. 255), "Dentro de um ambiente majoritariamente masculino e regido por padrões muitas vezes machistas, as mulheres são facilmente desacreditadas e enquadradas nas categorias de menor valor social." Nessa medida, identificam-se vários atributos negativos relacionados à infração feminina; a jovem infratora é mais facilmente enquadrada em uma delas do que naquelas de mais prestígio social. Tal circunstância contribui para a configuração de um cenário de preconceito e desrespeito, que se revela no desprezo às adolescentes que cometem atos infracionais, em especial, àquelas que apresentam comportamento visto como não-feminino (Torrão, 2005).

É importante salientar que aquilo que se observa hoje no sistema socioeducativo brasileiro, em relação à condição feminina, não é fenômeno isolado, mas produto de uma construção histórica e sociocultural. Quando abordamos a criminalidade feminina sob o ponto de vista histórico, identificamos nos estudos que surgem a partir do sec. XIX, a descrição das mulheres por meio de adjetivos depreciativos, tais como: amorais, enganosas, frias, calculistas e malévolas. Esse é o tom que perpassa a obra La Donna Delinquente, de Cesare Lombroso e Ferrero (1903), por exemplo. De alguma forma, percebe-se que esta visão da mulher não se alterou, de modo significativo, ao longo da história do pensamento criminológico. Segundo aponta Espinoza (2002, p.38), "A imagem da mulher foi construída como um sujeito fraco (em corpo e em inteligência), produto de falhas genéticas (postura na qual se baseia a criminologia positivista quando se ocupa da mulher criminosa)".

A ideia central que defendemos neste artigo é que, a exemplo da criminologia, os valores e crenças que perpassam a justiça juvenil caracterizam-se por concepções de gênero não equânimes, que naturalizam e hierarquizam as diferenças homem/mulher, ao passo que mantém o masculino como ponto de referência para a produção 
de significados sobre a violência e a infração. Em trabalho anterior de uma das autoras (Lopes de Oliveira \& Yokoy de Souza, 2012) abordou-se a 'cultura da cadeia', definida como o sistema de signos que orienta as instituições envolvidas na socioeducação. Em vez de propiciar a reflexão, a consciência e a emancipação, a cultura da cadeia leva à reprodução da desigualdade e a consolidação de trajetórias infracionais. Da mesma forma, pelos valores misóginos que faz implicitamente circular, a cultura da cadeia leva a contradições e à subtração de direitos das meninas. Por isso, questões de gênero devem ser objeto de mais investigação, no intuito de melhorar o atendimento socioeducativo às adolescentes. Este trabalho aborda o assunto a partir dos resultados de uma pesquisa (Costa, 2015) que investigou posicionamentos subjetivos sobre gênero e infração juvenil, desde a perspectiva de adolescentes do sexo feminino que cumpriam medida socioeducativa de internação, tema da pesquisa-intervenção (Castro \& Besset, 2008), aqui retratada.

A pesquisa-intervenção é nutrida pela perspectiva de que o intervir e o pesquisar são partes do um mesmo processo interpretativo, e que tanto deve contribuir para a transformação social dos grupos envolvidos (Prado, Oliveira, \& Oliveira Junior, 2008), como gerar indicadores para a produção de conhecimento relevantes para a área em que se realiza a investigação. No nosso caso, como parte de uma Oficina de Reflexão, realizada na Unidade de Internação em que as participantes cumpriam medida socioeducativa, foram realizados dez encontros, dos quais selecionamos para explorar, neste artigo, elementos que contribuem com essa segunda dimensão da pesquisaintervenção. Participaram do estudo 11 adolescentes, todas identificadas por meio de pseudônimos. A tabela a seguir apresenta algumas informações sobre essas adolescentes. 
Tabela 1: Caracterização das participantes do estudo (Costa, 2015)

\begin{tabular}{|c|c|c|c|c|c|}
\hline $\begin{array}{l}\text { Pseudônimo e } \\
\text { Idade }\end{array}$ & $\begin{array}{l}\text { Tempo de } \\
\text { internação }\end{array}$ & $\begin{array}{c}\text { Cumprimento } \\
\text { anterior de } \\
\text { M.S. }\end{array}$ & Filhos & $\begin{array}{c}\text { Nivel de } \\
\text { escolaridade }\end{array}$ & $\begin{array}{l}\text { Relacionamentos } \\
\text { durante a Oficina }\end{array}$ \\
\hline $\begin{array}{l}\text { Guacira } \\
18 \text { anos }\end{array}$ & $\begin{array}{c}1 \text { ano e } 05 \\
\text { meses }\end{array}$ & Năo & Não & $3^{\circ}$ ano E.M. & Sandra e Judith \\
\hline $\begin{array}{c}\text { Maria da Penha } \\
17 \text { anos }\end{array}$ & $\begin{array}{c}1 \text { ano e } 05 \\
\text { meses }\end{array}$ & Não & Não & $2^{\circ}$ ano E.M. & Chiquinha \\
\hline $\begin{array}{l}\text { Judith } \\
20 \text { anos }\end{array}$ & 11 meses & \begin{tabular}{|c|} 
Internação \\
Provisória; \\
Liberdade \\
Assistida; \\
Semiliberdade
\end{tabular} & Não & $2^{\circ}$ ano E.M. & Guacira \\
\hline $\begin{array}{c}\text { Chiquinha } \\
16 \text { anos }\end{array}$ & $\begin{array}{l}1 \text { ano e } 11 \\
\text { meses }\end{array}$ & Não & Não & 70 ano E.F. & Naomi e Maria da Penha \\
\hline $\begin{array}{c}\text { Naomi } \\
18 \text { anos }\end{array}$ & 10 meses & $\begin{array}{l}\text { Internação } \\
\text { Provisória; } \\
\text { Liberdade } \\
\text { Assistida }\end{array}$ & $\begin{array}{c}1 \text { filha } \\
(2 \text { anos })\end{array}$ & $9^{\circ}$ ano E.F & Chiquinha \\
\hline $\begin{array}{l}\text { Sandra } \\
15 \text { anos }\end{array}$ & $\begin{array}{l}1 \text { ano e } 04 \\
\text { meses }\end{array}$ & $\begin{array}{c}\text { Internação } \\
\text { Provisória; } \\
\text { Liberdade } \\
\text { Assistida } \\
\end{array}$ & Não & 70 ano E.F & Guacira \\
\hline $\begin{array}{c}\text { Rose Marie } \\
19 \text { anos }\end{array}$ & $\begin{array}{l}1 \text { ano e } 03 \\
\text { meses }\end{array}$ & $\begin{array}{l}\text { Internação } \\
\text { Provisória }\end{array}$ & $\begin{array}{c}1 \text { filho } \\
(2 \text { anos })\end{array}$ & $9^{\circ}$ ano do E.F. & Não informado \\
\hline $\begin{array}{c}\text { Maria Lacerda } \\
16 \text { anos }\end{array}$ & 05 meses & Não & $\begin{array}{c}1 \text { filha } \\
\text { (3 anos) }\end{array}$ & $\begin{array}{l}40 \text { ano do } \\
\text { Ensino } \\
\text { Fundamental }\end{array}$ & Não informado \\
\hline $\begin{array}{c}\text { Nísia Floresta } \\
19 \text { anos }\end{array}$ & 11 meses & Não & $\begin{array}{c}1 \text { filho } \\
\text { (2 anos) }\end{array}$ & $\begin{array}{l}9^{\circ} \text { ano do } \\
\text { Ensino } \\
\text { Fundamental }\end{array}$ & Não informado \\
\hline $\begin{array}{l}\text { Bertha } \\
16 \text { anos }\end{array}$ & 06 meses & Não & \begin{tabular}{|} 
Estava \\
grávida \\
de 7 \\
meses
\end{tabular} & $\begin{array}{l}7^{\circ} \text { ano do } \\
\text { Ensino } \\
\text { Fundamental }\end{array}$ & Não informado \\
\hline $\begin{array}{l}\text { Simone } \\
17 \text { anos }\end{array}$ & 06 meses & \begin{tabular}{|c|} 
Internação \\
Provisória; \\
Liberdade \\
Assistida e \\
Semiliberdade
\end{tabular} & Não & $\begin{array}{l}9^{\circ} \text { ano do } \\
\text { Ensino } \\
\text { Fundamental }\end{array}$ & Não informado \\
\hline
\end{tabular}

Os temas explorados em cada encontro relacionavam-se a aspectos pessoais, institucionais e sociais do cotidiano do atendimento socioeducativo e interfaces entre vivências e aspectos de gênero, motivados pela discussão de imagens, músicas e excertos literários em que as posições de gênero predominantes em nossa sociedade eram problematizadas. A mediação dos encontros buscou eliciar e possibilitar a negociação de significações em torno do processo socioeducativo e do próprio status das adolescentes nesse cenário. 


\section{Infração Juvenil Feminina Como Objeto da Psicologia: Entre o Enfoque Cultural e os Estudos de Gênero}

Como objeto da psicologia dos processos de desenvolvimento, a infração juvenil é concebida não apenas como ato ou conduta isolada, mas como complexo fenômeno de desenvolvimento humano (Lopes de Oliveira, 2006, 2015). Na adolescência, o conflito à lei situa-se em uma linha de continuidade com outros processos de ruptura, que devem ser compreendidos, por um lado, como questão subjetiva e, de outro, à luz do cenário sociocultural, político e econômico das contemporâneas sociedades urbanas. Nessas sociedades, a crescente importância tomada pelas práticas de consumo aliada aos dispositivos de exclusão e desqualificação social de alguns grupos (de classe, étnicos ou etários) com menor expressividade econômica leva a contradições importantes, que têm na infração juvenil uma de suas possíveis expressões.

Que contribuições encontramos na psicologia do desenvolvimento, que ajudem a explicar essa dupla dimensão do fenômeno da infração juvenil? $\mathrm{Na}$ sua origem, a concepção científica de desenvolvimento humano referia-se a uma sequência normativa de estágios universais. Ao longo do séc. XX, esta visão se transformou e, já no sec. XXI, abriu-se espaço para paradigmas teórico-metodológicos alternativos, que focalizam a totalidade da pessoa e em sua condição intrínseca de sujeito ativo (Branco \& Lopes de Oliveira, 2012; Zittoun, 2009, 2012). Neles, os processos de mudança pessoal na linha do tempo são compreendidos como algo dinâmico e complexo, interdependente da sociocultura e das interações concretas com a alteridade (Lopes de Oliveira, 2015). A ideia de que cada sujeito é ativo e atua na sua autoformação leva à compreensão de que o desenvolvimento humano individual é forjado em meio às relações dialéticas entre determinação e resistência às condições materiais e simbólicas de existência de cada sujeito, dadas as condições materiais e simbólicas de existência de cada um. Em cenários de precaríssimas condições socioeconômicas e culturais, a vivência repetida de adversidades, carências e violação de direitos favorece o empobrecimento dos vínculos intersubjetivos e comunitários, com efeitos deletérios sobre as subjetividades. Assim, nas sociedades que, como a nossa, se organizam em torno da capacidade de consumo de cada um, um consumo excessivo e desconectado da necessidade, a vulnerabilidade de grupos juvenis para a prática de atividades ilegais é aumentada. Nesse caso, as lacunas da educação e o pequeno espaço para a participação social e comunitária das novas gerações também compromete o desenvolvimento humano saudável e a transição para posições sociais mais autônomas e responsáveis.

A visão dos processos de desenvolvimento humano, acima delineada, converge com a Psicologia Cultural do Desenvolvimento (Branco \& 
Lopes de Oliveira, 2012; Mattos, 2013; Valsiner, 2012a, 2014). Trata-se de um modelo teórico sociogenético, no qual os processos de desenvolvimento sociopsicológico são representados por uma imagem que lembra a banda de Moebius (ou o símbolo do infinito), ressaltando a ideia de unidade e interdependência dos processos. Esta imagem é coerente com a ideia de que a dinâmica internalização - externalização é bidirecional, contínua e sistêmica. Nesta perspectiva, concebe-se cada membro da espécie humana como sendo ao mesmo tempo condicionado pela sociocultura e ativo participante na construção dos valores, costumes e modos de pensamento de sua comunidade. Os sujeitos são formados por um conjunto de regras do contexto estruturado no qual cresceu e, ao mesmo tempo, contribui para formar e transformar essas mesmas regras. Desse modo, o mundo é revelado ao sujeito como parte de um reservatório de signos, por meio do qual ele compreende as experiências, integrando-as em uma totalidade psicológica (Valsiner, 2012a, 2012b, 2014).

Esta unidade psicológica, também denominada 'sistema de self', 'self' simplesmente, ou 'subjetividade', forma-se à medida que as experiências no plano sociocultural são reconstruídas e convertidas em uma estrutura semiótica singular, individuada. A subjetividade constitui, assim, um processo ininterrupto e dinâmico de construção de si, mediado pelas interações com o outro, com os signos da cultura e com a realidade, face à crescente mediação da consciência pela reflexão (Zittoun, 2012). Entendemos que um dos campos semióticos por meio dos quais a cultura esculpe a subjetividade individual envolve os valores e as representações sociais de gênero (Lopes de Oliveira \& Camilo, 2014; Lopes de Oliveira \& Madureira, 2014; Madureira, 2007).

Os estudos de gênero caracterizam-se como um campo interdisciplinar, que necessita ser abordado segundo o olhar de diversas subáreas de conhecimento. A categoria conceitual gênero se assenta em uma base formada por elementos histórico-social, cultural e linguísticos diversos. Os estudos de gênero, a partir do advento do pensamento feminista, voltam-se a criticar o papel das principais instituições sociais na proposição de práticas e valores que têm sustentado, no curso da história, a constituição binária das identidades, em termos de masculino $x$ feminino. A partir da segunda metade do século XX, a epistemologia feminista começou a se afirmar como uma crítica à ótica, predominantemente masculina, presente na produção do conhecimento científico. Por isso, visou constituir um "projeto feminista de ciência alternativa" (Rago,1998). Sem nunca chegar a ser uma epistemologia dominante, foi incorporada à reflexão em várias disciplinas, às quais continua a prover um olhar político, ao possibilitar 0 avanço das reflexões sobre dimensões das (des)igualdades de gênero presentes em nossa sociocultura. 
Contudo, no que se refere à Psicologia e, especificamente, à Psicologia do Desenvolvimento, a epistemologia feminista teve pequeno impacto quando comparada a outros campos das ciências humanas e sociais. Como efeito, nessa ciência continuou-se a fomentar, muitas vezes, reflexões extemporâneas e equivocadas sobre as relações entre gênero, afetividade, identidade e sexualidade, para citar alguns. Por essas razões, considera-se que as questões de gênero compõem um tema necessitado de mais exploração teórica e empírica em Psicologia (Narvaz \& Koller, 2007; Lopes de Oliveira \& Madureira, 2014).

No cenário da produção do conhecimento psicológico, uma exceção aos equívocos na abordagem de questões de gênero deve ser feita aos trabalhos recentes de Madureira (2007) e Madureira \& Branco $(2012,2014,2015)$. As autoras tomam uma via peculiar que aproxima o tema do gênero à psicologia cultural do desenvolvimento humano, ao abordar a identidade de gênero como o produto vivo de negociações cotidianas entre sujeitos e "contextos culturais estruturados, perpassados por crenças, valores e práticas enraizadas historicamente, e que canalizam, de diferentes formas, os processos de significação" (Madureira \& Branco, 2015, p. 579). De acordo com as autoras, tais negociações se dão na linha fronteiriça entre diferentes sistemas simbólicos da cultura os quais ajudam a definir as experiências subjetivas aceitáveis ou reprováveis do ponto de vista do grupo social mais amplo, podendo contribuir para a inclusão das diversidades, ou ainda, para sua exclusão, discriminação e preconceito. O enfoque crítico do gênero preconizado pelos trabalhos em análise problematiza o binarismo de gênero e os sistemas de reprodução ideológica, a exemplo dos meios de comunicação de massa, que tem exercido um papel capital e estruturante na conformação da subjetividade, segundo o processo de se tornar homem ou mulher (Madureira \& Branco, 2012). A psicologia cultural do gênero defende que os sujeitos não agem apenas como "meros receptores, atingidos por instâncias externas e manipulados por estratégias alheias [...], são participantes ativos na construção de suas identidades" (Louro, 2010, p.25). Consideramos que esta forma de ver o fenômeno possibilita uma aproximação entre o tema da desigualdade de gênero e 0 atendimento socioeducativo às adolescentes autoras de infração, foco deste artigo, conforme veremos na sequência.

\section{A Adolescência e a I nfração J uvenil Feminina}

O reconhecimento de uma fase intermediária entre a infância e a condição adulta, hoje naturalizada nas sociedades ocidentais, é um fenômeno recente, associado à transição para a modernidade e que, 
ao longo do século $X X$, ganhou relevância como objeto de investigação científica, sobretudo nos campos da saúde e das ciências humanas e sociais (Yokoy de Souza, Lopes de Oliveira \& Rodrigues, 2014; Senna \& Dessen, 2014). Os primeiros estudos científicos sobre a adolescência veiculavam uma concepção predominantemente organicista, normativa e universalista da adolescência, ou seja, eram orientados pela visão de que esta condição era determinada pelas mudanças endócrinas, que alcançavam de modo similar a todos os seres humanos. Aspectos socioculturais e históricos eram costumeiramente desconsiderados nos primeiros ensaios teóricos sobre os fenômenos relacionados à adolescência e, de alguma forma, as representações sociais dominantes no campo social, ainda hoje, tem estreita relação com os pressupostos acima.

É importante salientar que as perspectivas sobre o desenvolvimento humano que nutrem a abordagem do fenômeno da adolescência, na Psicologia Cultural do Desenvolvimento, divergem da abordagem acima. Nesta última, enfatizam-se o entrelaçamento e a interdependência entre aspectos de caráter subjetivo (amadurecimento biológico e psicológico) e societais, na configuração de um conjunto de possibilidades e impedimentos ao desenvolvimento humano, nesse período da vida. Nesta direção, para se compreender o fenômeno da adolescência, na atualidade, é preciso abrir mão da busca de características universais e focalizar a análise no efeito de aspectos circunstanciais e específicos, tais como gênero, situação familiar, hierarquias sociais, relações institucionais e interpessoais, religião e classe socioeconômica, entre outros (Lopes de Oliveira, 2006). Como efeito da guinada de perspectiva aqui proposta, esta fase do curso de vida jamais deve ser confundida com um fenômeno homogêneo e previsível, mas um processo caracterizado pela diversidade e pluralidade das experiências e modos de subjetivação. As adolescências brasileiras são muitas e marcadas por diferentes graus de oportunidades e vulnerabilidades (Leite, 2013; Tomio \& Facci, 2009). Para os propósitos do presente estudo, vamos nos ater a um subgrupo particular dentro deste heterogêneo cenário, as adolescentes autoras de infração. De modo particular, consideraremos como as questões de gênero se entretecem à infração e buscaremos identificar e analisar as tramas de significados que concorrem para a produção da condição de invisibilidade e de dupla exclusão social das adolescentes que se envolvem em atos de violência e infração.

Como argumento inicial, consideramos que sob o enfoque psicológico, o fenômeno da infração juvenil é condicionado pelo mesmo conjunto de fatores que os que definem as possibilidades e os limites do desenvolvimento humano na adolescência, como um todo. A infração não é o que escapa ou excede à adolescência considerada 'normal', mas sim, faz parte de uma dinâmica mais ampla de fenômenos de 
mudança psicológica no curso da vida. No que se refere à adolescência, ela é marcada pela dialética diferenciação/identificação nas relações entre subjetividade (Eu) e alteridades (Outro/s). Diante de diferentes experiências e oportunidades, esta dialética pode se expressar em diferentes pontos de uma linha que vai do comportamento opositor e de questionamento inconsequente à autoridade, em uma ponta, até os comportamentos de risco, transgressivos, ou violentos, na outra. A infração, assim considerada, está relacionada a posicionamentos no sistema de self, que busca se organizar, desenvolver e sobreviver diante das contradições presentes em um universo sociocultural heterogêneo e perverso. Em outras palavras, a ação socioeducativa com adolescentes autores de infração é inócua se não puder interferir na trajetória de vida e desenvolvimento dos adolescentes, em geral.

No que se refere à abordagem criminológica do mesmo fenômeno, Brito (2007) identificou que, até meados do século XX, os delitos femininos eram inexpressivos, sendo protegidas pela justiça. Suas infrações, muitas vezes, eram mantidas no sigilo do âmbito doméstico, por meio de castigos e repreensões próprias. A partir da década de 1970, dá-se a mudança no perfil dos delitos femininos, que saem do ambiente privado da casa (furtos por empregadas domésticas ou parentes, agindo individual e furtivamente), para os ambientes públicos (roubos a lojas, shoppings, etc, começando a envolver ações em grupos e que se tornam, progressivamente mais lesivas). Nesse momento, observa Brito, na mesma obra, as punições se agravaram não apenas porque as infratoras passaram "a infringir regras penais, mas, sobretudo, a ofender a construção dos papéis de gênero" (p.51), ocupando as ruas e podendo agir de modo tão ofensivo quanto os homens.

No caso que se refere à infração feminina, além de caber tudo o mais que vimos sustentando, o envolvimento em atividades criminosas as expõe a outra condição simbólica peculiar, caracterizada pela dupla exclusão social, que se manifesta no contexto infracional e também no sistema socioeducativo: a primeira, diz respeito aos efeitos dos preconceitos e desigualdades de gênero que continuam a reservar às mulheres, em nossa sociedade, uma posição de menor valor social que os homens, apesar das ações em contrário; a segunda se refere à exclusão imposta às adolescentes que violam as expectativas sociais sobre a condição feminina que, de acordo com uma divisão binária dos papéis e características de gênero, é relegada ao cuidado, à maternagem e à subalternidade, caracterizando-se pela fragilidade, docilidade e sensibilidade. Em outras palavras, não se espera que as adolescentes cometam atos infracionais mais violentos, a exemplo de homicídio, latrocínio e/ou o comando do tráfico de drogas (Barcinski, 2009) e, diante da comprovada violação de expectativas, a reação 
social à infração juvenil feminina costuma ser mais crítica e rigorosa que aos meninos.

O crescimento da infração juvenil feminina e o impacto a presença de mais meninas no sistema socioeducativo, no Brasil e no mundo, levou a mudanças na abordagem sociojurídica do fenômeno, que culminou com o crescente encarceramento feminino, dispositivo que ao mesmo tempo atende a um pressuposto sancionatório (punir a adolescente que comete ato infracional) e retirar o problema não-resolvido da zona de visibilidade social.

Nesse aspecto, destaca-se que a invisibilidade é um fenômeno sociológico que se revela correlato às práticas de institucionalização, em especial, nas instituições totais e como contrapartida da lógica de defesa social (Baratta, 2013). Isso porque se refere ao processo pelo qual pessoas ou grupos estigmatizados (loucos, deficientes, dependentes químicos, infratores, entre outros) se tornam progressivamente desqualificados, desvalorizados, escondidos e, como efeito, consegue-se torná-los transparentes, invisíveis à sociedade. A invisibilidade pode ser produzida através de dispositivos de poder que legitimam a inserção desses grupos em cenários institucionais fechados, nos quais permanecem sob vigilância e em restrição de liberdade. A invisibilização tem o propósito de proteger a sociedade do perigo que representam alguns grupos, além de propiciar condições para que sejam corrigidos ou curados. Nesse sentido, exige de pesquisadores o esforço de compreensão do fenômeno e o compromisso de oferecer pistas para a qualificação mais ampla da atuação dos profissionais que atuam nesses contextos.

\section{Elaborações a partir dos resultados do estudo: abordando desigualdades de gênero no sistema socioeducativo}

Os registros em áudio dos encontros foram degravados e a primeira etapa da análise do material teve por norte a identificação de subconjuntos de temas, significados e questões apontados pelas participantes, com destaque para aquilo que informa sobre a experiência de ser mulher no sistema socioeducativo da unidade da federação investigada ${ }^{1}$. Esta etapa do trabalho interpretativo, após vários ensaios, levou à elaboração de um sistema de categorização das narrativas de pesquisa composto por quatro eixos, a saber: (a) (des) igualdade de direitos entre os gêneros; (b) estereótipos sobre o comportamento infracional feminino; (c) invisibilização da mulher; (d) impactos da lógica social repressiva sobre as adolescentes.

Tomando por balizadores cada um desses eixos, apresentamos e analisamos abaixo uma seleção de tópicos e trechos de narrativas de pesquisa que bem expressam os posicionamentos das adolescentes 
em relação àquelas crenças e práticas institucionais cotidianas da socioeducação, em que as questões de gênero se manifestam produzindo efeitos subjetivos e sociais diversos sobre elas, especialmente em seu cotidiano institucional.

a) A (Des) I gualdade de direitos entre os gêneros

"Nós temos os mesmos direitos que os meninos, mas só no papel. E pronto, acabou a história." (Maria da Penha, 06/11/2013).

O primeiro eixo reporta-se à tensão semiótica que as participantes notam haver entre os dispositivos normativos existentes (CF/88, Código Civil, lei Maria da Penha) que regulam as relações humanas e garantem igualdade de tratamento entre os gêneros, de um lado, e práticas sociais que reproduzem a desigualdade homem/mulher, de outro. A fala de Maria da Penha, acima, vem em seguida a um relato sobre as diferenças de tratamento entre os e as adolescentes, no que se refere ao direito e ao tempo dedicado, em cada caso, ao banho de sol naquela unidade de internação, onde os meninos tinham mais atividades ao ar livre que as meninas. Denota, da mesma forma, a percepção de que há pouco espaço para o debate dessas diferenças que, uma vez reproduzidas, violam direitos humanos básicos (Ramos, 2010).

Segundo Del Priori (2013), a matriz católica da formação moral de sociocultura brasileira sustentou, desde o início, o predomínio, simbólico e prático, do homem sobre a mulher; esta hierarquia de gênero continua a se manifestar em diversas instituições da atualidade, reproduzindo desigualdades, apesar das leis em contrário. No que se refere às instituições prisionais e da justiça juvenil, há um forte sistema de signos que correlacionam virilidade e conflito à lei (Coelho, 2013; Freitas, 2010). Agressividade e violência são naturalizadas como características hormonais do sexo masculino, de forma que a infração feminina é vista como algo exótico, imprevisto e desafiador, que contraria as crenças vigentes, e justificaria em muitos casos a aplicação de medidas de contenção mais gravosas. A nosso ver, esse sistema de concepções e crenças atua como barreira que impede, muitas vezes, o estabelecimento de interações respeitosas com as adolescentes, nesse contexto particular, fazendo crer que é mais difícil operacionalizar a ação socioeducativa com as do que com os adolescentes (Louro, 2010; Madureira \& Branco, 2014), tema que emerge nas narrativas discutidas a seguir. Ao mesmo tempo, a fala de Maria da Penha ilustra a percepção que as adolescentes têm de si, especialmente quando inseridas em um contexto fortemente marcado por uma cultura misógina (Lopes de Oliveira \& Yokoy de Souza, 2012). 
b) Estereótipos Sobre o Comportamento Infracional Feminino

"Eles dizem que mulher briga demais. Mas é que todo mundo aqui considera o módulo feminino o pior módulo. Que a gente... sei lá, moço... as pessoas têm muito preconceito com a gente porque a gente é mulher, entendeu... aqui, a gente, mulheres, não tem direito de nada..." (Naomi, em 06/11/2013).

$\mathrm{Na}$ Oficina, as adolescentes se tornaram porta-vozes de várias representações sociais negativas sobre a mulher disseminadas em nossa cultura, formas explícitas ou dissimuladas de se desvalorizar o sistema de valores e afetos que caracterizam o universo feminino. Elas se referem aos estereótipos da mulher como encrenqueira, emotiva e barulhenta, e indicam que tais estereótipos são continuamente reproduzidos e legitimados no contexto socioeducativo. Esse aspecto pode ser notado entre os profissionais que atuam nesse cenário, onde é comum se escutar sobre a preferência pelo trabalho junto aos módulos masculinos, em virtude do rol de problemas relacionados ao módulo feminino.

A misoginia pode ser entalhada na cultura por meio de diferentes dispositivos socioculturais e simbólicos, tais como: discursos pedagógicos, representações da mídia, imagens da propaganda, e mesmo nas interações humanas concretas (Fávero, 2010; Mendes, 2014). Também a ciência está implicada no problema, podendo contribuir para agravá-lo, quer por omissão ou por afirmação de verdades científicas moralmente enviesadas (Lopes de Oliveira \& Madureira, 2014). Em suas correntes mais tradicionais, as ciências humanas e sociais fomentaram estudos que contribuíram para as formas de preconceito descritas acima; na atualidade, comportam igualmente estudos críticos, voltados à explicação do caráter multifacetado da sexualidade e do gênero, assim como os que buscam descortinar valores, crenças, relações de poder e práticas socioinstitucionais que permeiam a discriminação de gênero (Louro, 2010; Louro, Felipe \& Goellner, 2013; Madureira, 2007; Madureira \& Branco, 2012, 2014).

Apesar dos avanços visíveis, no entanto, estamos longe de testemunhar o fim da opressão feminina e do preconceito contra as mulheres. E, da mesma forma que na sociedade em geral, as relações de gênero encontram nas instituições socioeducativas condições propícias para a manutenção de desigualdades que, em última instância, impedem a autonomia, a participação e a crítica consubstanciada das adolescentes sobre seu futuro e lugar na sociedade. 
c) A Invisibilidade Feminina no Sistema Socioeducativo

“Nós somos esquecidas pelo sistema, pela justiça... ninguém olha pra nós. Nós só fica aqui presa. Isso é uma forma de isolar a gente."

(Maria da Penha, em 30/10/2013).

A presente categoria da pesquisa corrobora o aspecto apontado acima, de que as medidas privativas de liberdade tornam os/as adolescentes invisíveis à sociedade. E, tal como argumentamos antes, estando o sistema despreparado e desmotivado para acolher a infração juvenil feminina, as adolescentes são ainda mais invisíveis que os adolescentes, uma condição que contribui para a solidão, 0 isolamento e a privação de direitos. Á época da coleta de dados de pesquisa, o sistema socioeducativo da unidade da federação investigada passava por uma profunda mudança que traria, entre outras novidades, a construção de uma unidade de internação exclusivamente feminina. Enquanto esta não se concluía, as adolescentes ocupavam um dos módulos de uma unidade masculina, onde as condições físicas e estruturais eram efetivamente precárias, sem o acesso a atividades educacionais e de profissionalização, aspecto que contribuiu para alguns dos posicionamentos evidenciados aqui.

Em texto que trata das mudanças relacionadas à justiça para mulheres, Baratta (1999) aponta que, na atualidade, a criminalidade feminina tende a ser abordada pela justiça com maior severidade. No contexto investigado, o sistema de justiça juvenil tende a ser mais indiferente às necessidades e interesses das adolescentes (no que se refere às oportunidades de formação e profissionalização, por exemplo) e, muitas vezes, age com mais rigorosidade na prevenção e punição da indisciplina feminina do que ocorreria com os adolescentes. Desse modo, o sistema reproduz desigualdades favorecendo com que elas acabem por encontrar na socioeducação oportunidades ainda mais estreitas que os adolescentes, para o desenvolvimento de trajetórias de vida que tomem direção diversa a da infração juvenil (Baratta, 1999; Espinoza, 2002; Faccio \& Camacho, 1995; Ramos, 2010).

d) Impactos da lógica social repressiva sobre as adolescentes.

“Eles quer tratar nós que nem se nós tivesse no sistema prisional. A gente tem que andar de mão pra trás e cabeça baixa. Olhando pro chão. [...] As pessoas fala que aqui é o socioeducativo, mas as pessoas não são educadas com a gente." (Maria da Penha, em 06/11/2013). 
"Eles acha que aqui é a [nome da penitenciária feminina local]." (Rose Marie, em 06/11/2013).

Um segundo efeito do despreparo e da intolerância do sistema socioeducativo à infração feminina se revela na exacerbação de práticas repressivas presentes no cotidiano, conforme revelam Maria da Penha e Rose Marie. Em outras palavras, transparece no sistema socioeducativo investigado indicadores de um modelo de justiça retributiva, ainda que os princípios normativos e pedagógicos da socioeducação sejam de caráter emancipatório. Segue-se a mesma lógica de atendimento definida em torno do controle da segurança, que no sistema prisional, justifica o tratamento arbitrário e a perene violação de direitos (Ramos, 2010).

Maria da Penha refere-se aos mecanismos de controle institucional utilizados com os/as adolescentes: mão pra trás e cabeça baixa, olhando para o chão. No caso, ela demonstra reconhecer a orientação punitiva que transparecem nos dispositivos de controle do corpo. $O$ sistema socioeducativo busca disciplinar e regular o movimento dos corpos, em lugar de fomentar a reflexividade e a tomada de consciência, necessários à transformação pessoal e à participação social e comunitária das adolescentes, em novas bases. Percebe que o controle do corpo feminino (expresso na moda, no conceito de 'roupa íntima', no significado moral da virgindade e na regulação da libido feminina) é um dispositivo social e historicamente adotado a fim de instituir uma moral feminina. De igual modo, as normas institucionais das unidades de internação que desencorajam as interações entre adolescentes de ambos os sexos e delas com os/as educadores/as, reprimem e artificializam os vínculos socioeducativos, o que acaba sendo outra forma de punição.

\section{Considerações finais}

De acordo com a Resolução 119/2006 do CONANDA, a Medida Socioeducativa deve contribuir para o desenvolvimento pleno da/do adolescente, de forma a propiciar o acesso aos direitos e às oportunidades de superação de uma situação de exclusão. A Declaração Universal dos Direitos Humanos (1948), por sua vez, legitimou valores que foram adotados por inúmeros diplomas, sistemas e ordenamentos jurídicos. Liberdade, solidariedade, justiça social, responsabilidade e respeito à diversidade são alguns dos valores norteadores de uma prática que garanta a todos o direito pleno de todo ser humano. Seguindo-os à risca, o atendimento socioeducativo tem o dever de garantir ao/à adolescente o seu reconhecimento como um sujeito pertencente, social e culturalmente, a uma coletividade. Entretanto, conforme os resultados de pesquisa 
interpretados acima permitem apontar, se são grandes as dificuldades encontradas, pelos adolescentes, para transformações e mudanças de trajetórias de vida que visem à reinserção social, para as adolescentes, estas dificuldades parecem ainda maiores.

Os resultados apresentados, embora se refiram a um estudo de caso único, não divergem dos resultados encontrados em outras pesquisas no âmbito da infração juvenil feminina, nos quais, diferentemente da prerrogativa da lei, verificou-se que as adolescentes que cometem atos infracionais estão expostas a diferentes facetas, subliminares e naturalizadas na cultura, de (re)produção das desigualdades de gênero. Embora aqui se tenha explorado uma parcela muito pequena dos resultados, é possível constatar que as adolescentes estão submetidas a preconceito por parte dos atores institucionais e também dos adolescentes. Tais aspectos, evidenciados nos dados empíricos, refletem os valores patriarcais que atravessaram os tempos, favorecendo a violação dos direitos das mulheres, que tem efeitos concretos sobre as práticas do sistema de justiça (criminal e juvenil) e, secundariamente, impede que as adolescentes assumam posições ativas, como mulheres e cidadãs, no enfrentamento à violência de gênero. Ademais, abordar a infração feminina em um cenário majoritariamente masculino tem efeitos visíveis na institucionalização da subjetividade das adolescentes. Por isso, a investigação realizada procurou possibilitar a produção de saber sobre elas e sobre o lugar que ocupam dentro do SSE, a partir de suas próprias perspectivas.

Em suma, a investigação propôs elucidar as bases do problema das desigualdades de gênero por meio de uma articulação teórica entre a perspectiva da psicologia sociocultural e os estudos de Gênero, tendo conduzido a indicadores de que o sistema socioeducativo contribui, não apenas, para legitimar a (re)produção de estereótipos de gênero na linha dos que já existem em nossa sociocultura, como também para a proliferação de ideologias sexistas e misóginas, que contribuem para afastar as adolescentes das chances de construção de novas trajetórias de desenvolvimento, em direção alternativa à prática de infração.

\section{Referências}

Abramovay, M., Cunha, A. L., Calaf, P. P., Carvalho, L. F. D., Castro, M. G., Fefferman, M., \& Maciel, M. (2010). Gangues, gênero e juventudes: donas de rocha e sujeitos cabulosos. Brasília: Secretaria de Direitos Humanos.

Assis, S. G., \& Constantino, P. (2001). Filhas do mundo: infração juvenil feminina no Rio de Janeiro. Rio de Janeiro: Fundação Oswaldo Cruz. 
Baratta, A. (1999). Paradigma do Gênero: da questão criminal à questão humana. In Campos, C. (Eds.). Criminologia e Feminismo. Porto Alegre: Sulina.

Baratta, A. (2013). Criminologia crítica e crítica do Direito penal: introdução à sociologia do direito penal. Rio de Janeiro: ICC/Revan.

Barcinski, M. (2009). Centralidade de gênero no processo de construção da identidade de mulheres envolvidas na rede do tráfico de drogas. Ciência \& Saúde Coletiva, 14(5), 1843-1853.

Branco, A. U., \& Lopes de Oliveira, M. C. S. (2012). (Eds.). Diversidade e cultura da paz na escola: contribuições da perspectiva sociocultural. Porto Alegre: Mediação.

Brasil. (1990). Lei no 8.069/1990. Estatuto da Criança e do Adolescente. Disponível em: http://www.planalto.gov.br/ccivil_03/LEIS/L8069.htm Acesso em: 17 ago. 15.

Brasil. (1998). Constituição da República Federativa do Brasil de 1988. Disponível em: http://www.planalto.gov.br/ccivil_03/Constituicao/Constituicao. htm Acesso em: 17 ago. 15.

Brasil, Sistema Nacional de Atendimento Socioeducativo. (2006). Resolução $n^{\circ} 119$, do Conselho Nacional dos Direitos da Criança e do Adolescente, 11 de dezembro de 2006. Dispõe sobre o Sistema Nacional de Atendimento Socioeducativo e dá outras providências. Disponível em: http://www.crianca. mppr.mp. br/arquivos/File/download/resoluc ao_119_conanda_sinase.pdf Acesso em: 17 ago. 2015.

Brasil, Sistema Nacional de Atendimento Socioeducativo. (2012). Lei 12594, Institui o Sistema Nacional de Atendimento Socioeducativo (SINASE), regulamenta a execução das medidas socioeducativas destinadas a adolescente que pratique ato infracional. Disponível em: http://www. planalto.gov.br/ccivil_03/_ato20112014/2012/lei//12594.htm Acesso em: 17 ago. 2015.

Brito, E. Z. C. de (2007). Justiça e Gênero: uma história da justiça de menores em Brasília (1960-1990). Brasília: UnB.

Castro, L. R. de, \& Besset, V. L. (Eds.). (2008). Pesquisa-intervenção na infância e juventude. Rio de Janeiro: NAU.

Coelho, J. P. L. (2013). Estudo sobre a dinâmica de organização do "si mesmo" de adolescentes do sexo feminino em conflito com a lei' (Dissertação de Mestrado). Universidade Federal do Ceará, Fortaleza, Brasil.

Costa, D. L. P. C de O. (2015). As adolescentes e a medida socioeducativa de internação: rompendo o silêncio (Dissertação de Mestrado). Universidade de Brasília, Brasília, Brasil. 
Del Priori, M. (2013). Histórias e conversas de mulher. São Paulo: Planeta.

Espinoza, O. (2002). A Prisão Feminina desde um Olhar da Criminologia Feminista. Revista Transdisciplinar de Ciências Penitenciárias. 1(1), 35-39.

Faccio, A. \& Camacho, R. (1995). Em busca das mulheres perdidas ou uma aproximação - crítica à criminologia. In Mulheres: vigiadas e castigadas (pp. 26-64). São Paulo: CLADEM Brasil.

Fávero, M. H. (2010). Psicologia do Gênero. Psicobiografia, Sociocultura e Transformações. Curitiba: Editora da Universidade Federal do Paraná.

Freitas, R. B. (2010) O Ato de Matar nas Trajetórias Juvenis: Trocas e Negociações Identitárias de Meninas Envolvidas na Prática de Homicídio (Tese de Doutorado). Universidade Federal do Ceará, Fortaleza, Brasil.

Leite, V. (2013). Sexualidade adolescente como direito? A visão de formuladores de políticas públicas. Rio de Janeiro: EdUERJ .

Lombroso, C. \& Ferrero, G. (1903). La Donna delinqüente: la prostituta e la donna normale. Torino: Fratelli Bocca.

Lopes de Oliveira, M. C. S. (2006). Identidade, Narrativa e Desenvolvimento na Adolescência: Uma Revisão Crítica. Psicologia em Estudo, 11(2), 427-436.

Lopes de Oliveira, M. C. S. (2015). Desenvolvimento do self e processos de hiperindividualização: interrogações à psicologia dialógica. Manuscrito em elaboração.

Lopes de Oliveira, M. C. S. \& Camilo, A. A. (2014). Participação política juvenil e constituição de gênero: uma questão para a psicologia do desenvolvimento. Athena Digital, 14(2), 95-115.

Lopes de Oliveira, M. C. S. \& Madureira, A. F. do A. (2014). Gênero e psicologia do desenvolvimento: quando a ciência é utilizada como força normatizadora das identidades de gênero. Brasília: Labrys.

Lopes de Oliveira, M. C. S. \& Yokoy de Souza, T. (2012). Education, Peace, or Jail Culture? What is Promoted by Institutions in Charge of Adolescents Involved With Criminal Activities. In J. Valsiner e A. U. Branco. (Orgs.). Cultural Psychology of Human Values. 1ed, v. 1 (pp. 239-264). Charlotte: Information Age Publishing.

Louro, G. L. (Eds.). (2010). O corpo educado: pedagogias da sexualidade. Belo Horizonte: Autêntica Editora.

Louro, G. L., Felipe, J. \& Goellner, S. (2013). Corpo, gênero e sexualidade: um debate contemporâneo na educação. Petrópolis, RJ : Vozes.

Madureira, A. F. A. \& Branco, A. U. (2012). As raízes históricoculturais e afetivas do preconceito e a construção de uma cultura democrática na escola. In Branco e Lopes de Oliveira 
(Orgs.). Diversidade e cultura da paz na escola: contribuições da perspectiva sociocultural ( $p p$. 125-155). Porto Alegre: Mediação.

Madureira, A. F. A \& Branco, A. U. (2014). Gênero, sexualidade e desenvolvimento humano: construindo uma cultura democrática na escola. In M. A. Dessen \& D. A. Maciel. (Orgs.), A ciência do desenvolvimento humano (pp. 145-171). Curitiba: Juruá.

Madureira, A. F. A. \& Branco, A. U. (2015). Genero, Sexualidade e Diversidade na Escola a partir da Perspectiva de Professores/as. Temas em Psicologia, 23(3), 577-591.

Madureira, A. F. A. (2007). Gênero, sexualidade e diversidade na escola: a construção de uma cultura democrática. Tese de Doutorado. Universidade de Brasília, Brasília - DF, Brasil.

Mattos, E. (2013). Desenvolvimento do self na transição para a vida adulta: um estudo longitudinal com jovens baianos. Tese de doutorado não publicada. Universidade Federal da Bahia, Salvador - BA, Brasil.

Mendes, S. R. (2014). Criminologia Feminista: novos paradigmas. Saraiva: São Paulo.

Navaz, M. G. \& Koller, S. H. A. (2007). Marginalização dos estudos feministas e de gênero na psicologia acadêmica contemporânea. Revista Psico, Porto Alegre, 38(3), 216-223.

Prado, M. A. M., Oliveira, M. M. de, \& Oliveira Jr, O. (2008). A pesquisa-intervenção e a emergência dos atores sociais: considerações a partir da experiência de jovens rurais. In L. R. Castro \& V. L. Besset. (Org.). Pesquisa-intervenção na infância e juventude (pp. 179-204). Rio de Janeiro: NAU.

Rago, M. (1998). Epistemologia Feminista, Gênero e História. In Pedro, Joana; Grossi, Miriam (Org.). Masculino, Feminino, Plural ( pp 316-342). Florianópolis: Ed. Mulheres.

Ramos, L. S. (2010). Como as meninas são (não) vistas pelo sistema de medidas socioeducativas do Distrito Federal. In Brasil. Situação dos Adolescentes privados de Liberdade. Centro de Defesa da Criança e do Adolescente. Brasília, DF.

Senna, S. R. \& Dessen, M. A. (2012). Contribuições das teorias do desenvolvimento humano para a concepção contemporânea da adolescência. Psicologia: Teoria e Pesquisa, 28(1), 101-108.

Tomio, N. A. O. \& Facci, M. G. D. (2009). Adolescência: uma análise a partir da Psicologia Sócio-Histórica. Revista Teoria e Prática da Educação, 12(1), 89-99.

Torrão Filho, A. (2005). Uma questão de gênero: onde o masculino e o feminino se cruzam. Cadernos Pagu, (24), 127-152.

Valsiner, J. (2012a). Cambridge Handbook of culture and psychology. New York: Oxford University Press, Inc. 
Valsiner, J. (2012b). Fundamentos de uma psicologia cultural: mundos da mente, mundos da vida. Porto Alegre: Artmed.

Valsiner, J. (2014). An invitation to cultural psychology. Sage Publications, Incorporated.

Yokoy de Souza, T. (2012). Processos de desenvolvimento de educadores sociais do sistema de medidas socioeducativas: indicadores de formação. Tese de Doutorado. Universidade de Brasília, Brasília, Brasil.

Yokoy de Souza, T., Lopes de Oliveira, M. C. S., \& Rodrigues, D. S. (2014). Adolescência como fenômeno social. In A. M. A. Medeiros \& C. Bisinoto (Eds.). Docência na Socioeducação (Vol. 1, pp. 119-129). Brasília: Universidade de Brasília.

Zittoun, T. (2009). Dynamics of Life-Course Transitions: A Methodological Reflection. In J. Valsiner, P. C. M. Molenaar, M. C. D. P. Lyra, N. Chaudhary (Eds.). Dynamic Process Methodology in the Social and developmental Sciences (pp. 405-429. New York, NY: Springer-Verlag.

Zittoun, T. (2012). On the Emergence of the Subject. Integrative Psychological and Behavioral, 46(3), 259-273.

\author{
Endereço para correspondência \\ Maria Cláudia Santos Lopes de Oliveira \\ Universidade de Brasília \\ Campus Darcy Ribeiro - ICC SUL, sala A1 - 010, Asa Norte, CEP 70910-900, \\ Brasília, DF, Brasil \\ Endereço eletrônico: mcsloliveira@gmail.com

\section{Daniela Lemos Pantoja Costa} \\ Universidade de Brasília \\ Campus Darcy Ribeiro - ICC SUL, sala A1 - 010, Asa Norte, CEP 70910-900, \\ Brasília, DF, Brasil \\ Endereço eletrônico: danim23@uol.com.br

\section{Carolina Knihs de Camargo} \\ Universidade de Brasília \\ Campus Darcy Ribeiro - ICC SUL, sala A1 - 010, Asa Norte, CEP 70910-900, \\ Brasília, DF, Brasil \\ Endereço eletrônico: carolinak.camargo@gmail.com
}

Recebido em: 17/05/2017

Reformulado em: 07/06/2017

Aceito em: 22/06/2017

\title{
Notas
}

* Psicóloga (Universidade Federal Fluminense, 1986), Mestrado em Psicologia (PUC-Rio, 1992) e Doutorado em Educação (PUC-Rio, 2000), tendo realizado estágios de pós-doutorado em Desenvolvimento Humano na Clark University, Worcester (MA), E.U.A. (2005), em Psicologia na Universidade Autônoma de Madri, Espanha (2009) e na Universidade de Aalborg, Dinamarca, 2016. É Professora Associada da Universidade de Brasília, onde desenvolve projetos de pesquisa na área de Psicologia do Desenvolvimento Humano no curso de vida, com ênfase no 
desenvolvimento social no contexto urbano, das escolas e instituições do sistema de garantia de direitos, tais como as unidades de atendimento socioeducativo. Coordena o LABMIS - Laboratório de Psicologia Cultural e o GT Psicologia Dialógica (ANPEPP).

** Mestre em Processos de Desenvolvimento Humano e Saúde pelo Instituto de Psicologia da Universidade de Brasília (2015). Possui graduação em Letras - Inglês pelo Centro Universitário de Brasília (1997), e Especialização em Metodologia de Ensino da Língua Portuguesa pela Universidade Gama Filho (2010). É professora concursada da SEE-DF desde 2000, sendo que, de 2003 até a presente data, atua em escolas em Unidades de Internação Provisória e de Medida Socioeducativa de Internação, como professora de Língua Inglesa e Língua Portuguesa. Tem interesse em estudos nas áreas de Educação, Gênero, Psicologia do Desenvolvimento e Socioeducação.

*** Carolina Camargo é Psicóloga e Bacharel em Psicologia graduada pela Universidade de Brasília (UnB). Realizou PIBIC sob orientação da Profa. Dra. Maria Cláudia na área de adolescência, desenvolvimento e lei Maria da Penha. Trabalha em Brasília como psicóloga clínica, com ênfase no atendimento de vítimas de trauma e violência.

${ }^{1}$ A unidade de internação investigada é a única a receber adolescentes do sexo feminino na referida unidade da federação.

Este artigo de revista Estudos e Pesquisas em Psicologia é licenciado sob uma Licença Creative Commons Atribuição-Não Comercial 3.0 Não Adaptada. 